\title{
Dietary Phospholipid-Dependent Reductions in Gene Expression and Activity of Liver Enzymes in Fatty Acid Synthesis in Fasted-Refed Rats
}

\author{
Isabelle A. RouYer, Yoko TAKAHASHI and Takashi IDE* \\ Laboratory of Nutrition Biochemistry, National Food Research Institute, \\ Ministry of Agriculture, Forestry and Fisheries, Tsukuba Science City, \\ Ibaraki 305-8642, Japan
}

(Received October 19, 1998)

Summary The effects of dietary soybean phospholipid, its hydrogenation product and safflower phospholipid on gene expression and the activity of hepatic enzymes in fatty acid biosynthesis were examined in fastedrefed rats. Phospholipid composition of soybean phospholipid and its hydrogenation product were the same, but the hydrogenation product contained negligible amounts of unsaturated fatty acids. Among phospholipid classes, lysophosphatidylcholine and phosphatidylinositol proportions were slightly higher in safflower phospholipid than in soybean phospholipid or its hydrogenation product. Rats were fasted for $2 \mathrm{~d}$ and refed a fat-free diet or a diet containing $4 \%$ fatty acids either as soybean oil or various phospholipid preparations for $3 \mathrm{~d}$. Compared to the fat-free diet, the soybean oil diet only slightly decreased specific, but not total hepatic fatty acid synthetase and malic enzyme activity, and it was totally ineffective in modulating glucose 6-phosphate dehydrogenase and pyruvate kinase activity under our experimental conditions. The diets containing phospholipids, however, markedly decreased the activity of these enzymes. The extent of reduction was somewhat attenuated with hydrogenated soybean phospholipid as compared with soybean and safflower phospholipids. Dot and Northern blot hybridization using specific cDNA probes showed that, compared to a fat-free diet, diets containing phospholipids profoundly decreased the hepatic mRNA levels of enzymes in fatty acid synthesis. Soybean oil, however, only marginally affected these parameters. Hepatic mRNA levels for enzymes correlated well with enzyme activity. Dietary phospholipids therefore appear to have decreased enzyme activity in fatty acid synthesis primarily by suppressing the mRNA levels of these enzymes. Compared to soybean oil, hydrogenated soybean phospholipid is still effective in decreasing the activity and mRNA level of enzymes in fatty acid synthesis. Therefore, it is difficult to ascribe the

*To whom correspondence should be addressed. E-mail: idetaka@nfri.affrc.go.jp 
potent physiological activity of phospholipid in reducing fatty acid synthesis entirely to polyunsaturated fatty acid moiety.

Key Words dietary phospholipid, gene expression, fatty acid synthesis

We have demonstrated (1-5) that dietary soybean phospholipid decreased parameters of triacylglycerol synthesis in the rat liver. Detailed studies have demonstrated unequivocally that reduction in the activity of hepatic enzymes in the fatty acid synthetic pathway is primarily responsible for dietary soybean phospholipid-dependent reduction in triacylglycerol synthesis in the liver. It was also demonstrated $(1,3)$ that phospholipid preparation of egg yolk origin also decreased parameters of triacylglycerol synthesis and the hepatic activity of enzymes in fatty acid synthesis in the rat. Conceivably, therefore, phospholipids originating from other origins may be equally effective in decreasing hepatic fatty acid synthesis. The observation that both phospholipids originating from soybean and egg yolk and those originating from mold (6) and safflower seed (7-9) are also effective in decreasing serum lipid levels in the rat support this possibility, but confirmation remains to be sustained.

Polyunsaturated fatty acids decrease the activity and gene expression of enzymes in hepatic fatty acid synthesis more than saturated and monounsaturated fatty acids (10-15). Polyunsaturated fatty acids such as linoleic or $\alpha$-linolenic acids, the predominant components of soybean phospholipid, may thus possibly be responsible for phospholipid physiological activity in decreasing hepatic fatty acid synthesis. Our observations, however, showed that a diet containing soybean oil or a fat mixture simulating the soybean phospholipid fatty acid composition was much less effective in decreasing the activity of enzymes in fatty acid synthesis $(2,3)$. These results thus indicate that component(s) other than polyunsaturated fatty acids may be primarily responsible for the potency of dietary phospholipid in decreasing hepatic fatty acid synthesis. If this is correct, the hydrogenation of phospholipid may not eliminate the physiological activity of this lipid molecule in decreasing hepatic lipid biosynthesis parameters in the rat. This also remains to be confirmed however.

Available evidence indicates that nutritional and physiological conditions alter the hepatic abundance of mRNAs for enzymes in fatty acid synthesis, and thus modify hepatic fatty acid synthesis $(10,11)$. Conceivably then, a dietary phospholipid-dependent decrease in fatty acid synthesis is ascribable to the modified gene expressions of enzymes in fatty acid synthesis, but information confirming this effect is lacking.

Given the above, we studied the effects of soybean phospholipid, its hydrogenation product, and safflower phospholipid on mRNA abundance and enzyme activity in fatty acid synthesis in the liver of fasted-refed rats. 


\section{MATERIALS AND METHODS}

Materials. Dietary lipids used were soybean oil (Wako Pure Chemicals, Osaka, Japan), soybean phospholipid (Taiyo Kagaku Co., Yokkaichi, Japan) hydrogenated soybean phospholipid (Taiyo Kagaku Co.), and safflower phospholipid (Rinoru Oil Mills Co., Nagoya, Japan). Phosphorus and fatty acid contents of the phospholipid preparations were equivalent (Table 1). Soybean and safflower phospholipids are enriched with polyunsaturated fatty acids. Hydrogenated soybean phospholipid contains negligible amounts of polyunsaturated fatty acids. Soybean phospholipid contains a significant amount of $\alpha$-linolenic acid, but only a trace amount of the $n-3$ octadecatrienoic acid was detected in the safflower phospholipid. Phospholipid compositions were equivalent for the soybean phospholipid and its hydrogenation product. Compared to soybean phospholipid, safflower phospholipid contained less phosphatidylethanolamine but more lysophosphatidylcholine and phosphatidylinositol. $\left[\alpha^{-32} \mathrm{P}\right] \mathrm{dCTP}$ and nylon filtrate $\left(\right.$ Hybond $\left.\mathrm{N}^{+}\right)$were purchased from Amersham International, Bucks, UK. Malonyl-CoA was purchased from Sigma Chemicals (St. Louis, MO, USA). ADP, NADPH and 6-phosphogluconate

Table 1. Phospholipid and fatty acid compositions of dietary lipids.

\begin{tabular}{|c|c|c|c|c|}
\hline & \multicolumn{4}{|c|}{ Dietary lipids } \\
\hline & $\begin{array}{l}\text { Soybean } \\
\text { oil }\end{array}$ & $\begin{array}{c}\text { Soybean } \\
\text { phospholipid }\end{array}$ & $\begin{array}{l}\text { Hydrogenated } \\
\text { soybean } \\
\text { phospholipid }\end{array}$ & $\begin{array}{c}\text { Safflower } \\
\text { phospholipid }\end{array}$ \\
\hline Phosphorous content $(\mu \mathrm{mol} / \mathrm{g})$ & - & 979 & 1,072 & 1,031 \\
\hline \multicolumn{5}{|l|}{ Phospholipid classes $(\mathrm{mol} \%)$} \\
\hline Lysophosphatidylcholine & - & 4.5 & 3.6 & 11.8 \\
\hline Phosphatidylcholine & - & 32.5 & 36 & 31.8 \\
\hline Phosphatidylinositol & - & 16 & 14.8 & 22.2 \\
\hline Phosphatidylserine & - & 1 & 1.4 & 1.6 \\
\hline Phosphatidylethanolamine & - & 34.7 & 35.5 & 21.6 \\
\hline Phosphatidic acid & - & 11.2 & 8.6 & 10.9 \\
\hline Fatty acid content $(\mathrm{mg} / \mathrm{g})$ & 938 & 638 & 603 & 620 \\
\hline \multicolumn{5}{|c|}{ Fatty acid composition (weight \%) } \\
\hline $14: 0$ & 0.2 & 0.3 & 0.3 & 0.5 \\
\hline $16: 0$ & 10 & 19.7 & 22.1 & 21.7 \\
\hline 18:0 & 3.5 & 4 & 68.5 & 4.3 \\
\hline $18: 1$ & 24.4 & 8.6 & 8.5 & 6.2 \\
\hline $18: 2$ & 53.5 & 59.2 & 0.2 & 66.7 \\
\hline $18: 3$ & 8.2 & 7.9 & - & 0.3 \\
\hline $20: 0$ & - & 0.4 & 0.4 & 0.4 \\
\hline
\end{tabular}


dehydrogenase (EC 1.1.1.44) were purchased from Oriental Yeast Co., Tokyo, Japan. Animals and diets. Male Sprague-Dawley rats (Charles River Japan, Kanagawa, Japan) were housed individually in a room with controlled temperature $\left(20-22^{\circ} \mathrm{C}\right.$ ), humidity $(55-65 \%)$, and lighting (light from 07:00 to 19:00), and fed a commercial nonpurified diet (NMF, Oriental Yeast Co.). After $7 \mathrm{~d}$ of acclimatization to housing conditions, the rats were randomly divided into 5 groups consisting of 7 animals each, fasted $2 \mathrm{~d}$, and then refed purified experimental diets (a fat-free diet or diets containing lipid preparations) for $3 \mathrm{~d}$. The basal composition of the experimental diet was, in weight percent: casein, 20; corn starch, 15; cellulose, 2; mineral mixture, 3.5; vitamin mixture, 1.0; DL-methionine, 0.3; choline bitartrate, 2; and sucrose to 100. Mineral and vitamin mixture compositions used were those recommended by the American Institute of Nutrition (16). The amounts of dietary lipids added to the experimental diets were $4.3 \%$ for soybean oil and $6.3-6.6 \%$ for the phospholipid preparations. These amounts provided the same amount of fatty acids $(4 \%)$ in the diets. We followed our institute's guidelines for laboratory animal care and use.

Enzyme assays. At the end of the experiments, rats were anaesthetized using diethyl ether and sacrificed by bleeding from the abdominal aorta, after which the livers were immediately excised. A portion of each liver (approximately $1.5 \mathrm{~g}$ ) was homogenized with $10 \mathrm{~mL}$ of $0.25 \mathrm{~m}$ sucrose solution containing $1 \mathrm{~mm}$ EDTA and $3 \mathrm{~mm}$ Tris- $\mathrm{HCl}(\mathrm{pH} 7.2)$ and centrifuged at $200,000 \times g$ for $30 \mathrm{~min}$. The cytosolic fraction thus obtained was used to analyze the activity of fatty acid synthetase (17), glucose 6-phosphate dehydrogenase (EC 1.1.1.49) (18), malic enzyme (EC 1.1.1.40) (19), and pyruvate kinase (EC 2.7.1.40) (20).

Lipids analysis. Liver lipids were extracted and purified (21). Triacylglycerol and phospholipid contents in the extract were determined as described elsewhere (22). Cholesterol content in lipid extracts was determined enzymatically as described elsewhere (23).

Preparations of $c D N A$ probes. Reverse transcription and polymerase chain reaction (PCR) were used to prepare cDNA probes for fatty acid synthetase, glucose-6-phosphate dehydrogenase, malic enzyme, and L-type pyruvate kinase using a kit (Gene Amp ${ }^{\circledR}$ RNA PCR Kit; Perkin Elmer, Foster City, CA, USA) according to the procedures recommended by the manufacturer with slight modifications. First-strand cDNA was synthesized from $200 \mathrm{ng}$ of rat liver poly $(\mathrm{A})^{+}$ RNA prepared using oligo(dT) cellulose column chromatography. After initial denaturation at $94^{\circ} \mathrm{C}$ for $5 \mathrm{~min}$, cDNA was amplified as follows: denaturation at $94^{\circ} \mathrm{C}$ for $1 \mathrm{~min}$, annealing at $55^{\circ} \mathrm{C}$ for $2 \mathrm{~min}$, and extension at $72^{\circ} \mathrm{C}$ for $3 \mathrm{~min}$. Thirty cycles were used for amplification. Upon completion of the last cycle, the mixture was incubated at $72^{\circ} \mathrm{C}$ for $10 \mathrm{~min}$. Specific sense and antisense primers used for the preparation of cDNAs by PCR are shown in Table 2. Primers were chosen from cDNA sequences available in the GenBank database (accession numbers: fatty acid synthetase, J03514; glucose 6-phosphate dehydrogenase, X07467; L-type pyruvate kinase, M17685) except for malic enzyme whose primers were chosen from the 


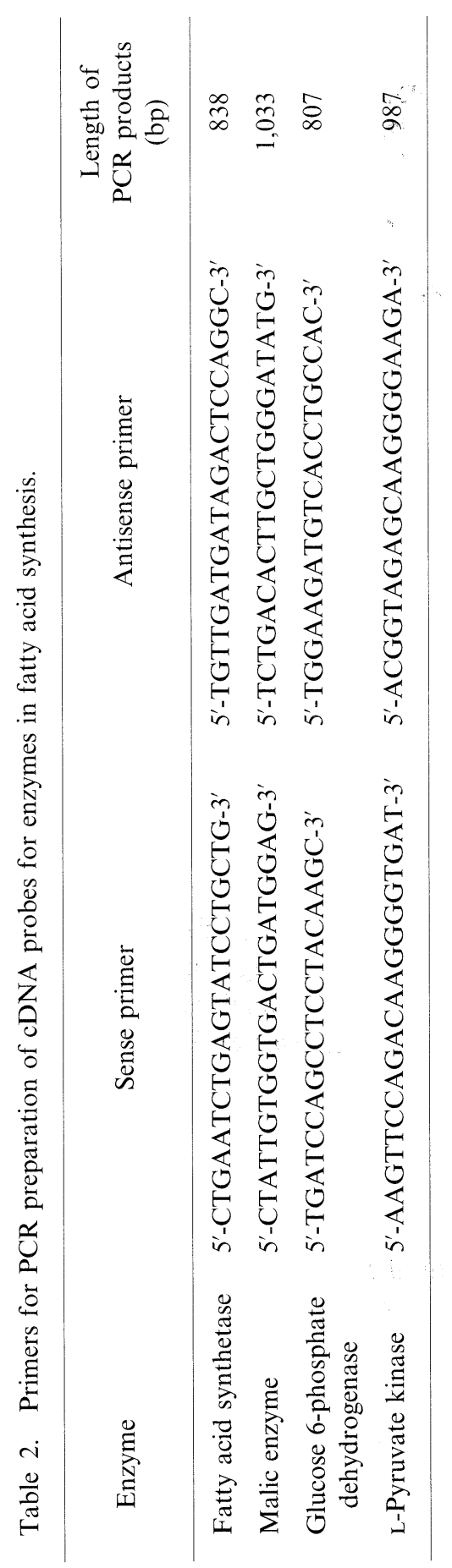

Vol 45, No 3, 1999 
cDNA sequence reported by Magnuson et al (24). DNA sequences of the amplification products were partially determined by direct sequencing to confirm their identities with reported cDNA sequences of corresponding enzymes. PCR products were purified by agarose gel electrophoresis and used for probes to detect mRNAs for enzymes. The cDNA probe for $\beta$-actin was provided by Wako Pure Chemicals.

RNA analysis. Hepatic RNA was extracted using the acid guanidium thiocyanate-phenol-chloroform method (25). RNA preparation quantity and purity were estimated by analyzing absorbance at 260 and $280 \mathrm{~nm}$. RNA samples $(40 \mu \mathrm{g})$ were denatured and applied to a nylon filter (Hybond $\mathrm{N}^{+}$, Amersham International) using a dot-blot apparatus purchased from Bio-Rad Laboratories (Hercules, CA, USA) and fixed with UV irradiation. Northern blot analysis was conducted by standard procedures. RNA samples $(40 \mu \mathrm{g})$ were denatured and electrophoresed on a $1.1 \%$ agarose gel containing $0.66 \mathrm{M}$ formaldehyde, transferred to a nylon membrane and fixed with UV irradiation. Equal loading and integrity of the RNA sample were confirmed by ethidium bromide fluorescence of ribosomal $18 \mathrm{~S}$ and $28 \mathrm{~S}$ RNAs. cDNA probes were labeled with $\left[\alpha-{ }^{32} \mathrm{P}\right] \mathrm{dCTP}$ using a random primer DNA labeling kit (Random Primer DNA Labeling Kit Ver. 2.0; Takara Co., Kyoto, Japan). Nylon filters were prehybridized for at least $5 \mathrm{~h}$ at $42^{\circ} \mathrm{C}$ in a medium containing $0.75 \mathrm{M}$ $\mathrm{NaCl}, 75 \mathrm{~mm}$ sodium citrate, $5 \times$ Dehardt's solution, $1 \% \operatorname{SDS}(\mathrm{w} / \mathrm{v}), 0.05 \%$ denatured salmon sperm DNA (w/v), and $50 \%$ formamide $(\mathrm{v} / \mathrm{v})$, and then radiolabeled probes were added to give concentrations exceeding $2 \times 10^{6} \mathrm{dpm} / \mathrm{mL}$. Hybridization was carried out for $16-20 \mathrm{~h}$ at $42^{\circ} \mathrm{C}$. Filters were washed twice with a medium containing $0.3 \mathrm{M} \mathrm{NaCl}, 30 \mathrm{~mm}$ sodium citrate, and $0.1 \% \mathrm{SDS}$ at room temperature, and then 4 times with a medium containing $30 \mathrm{~mm} \mathrm{NaCl}, 3 \mathrm{~mm}$ sodium citrate, and $0.1 \% \mathrm{SDS}$ at $65^{\circ} \mathrm{C}$. Filters were exposed to an imaging plate (Bio-Rad Laboratories) for 16-20 h. RNA hybridized with specific cDNA probes were analyzed and quantified by an imaging analyzer (Bio-Rad Laboratories).

Statistical analysis. Data was analyzed by one-way analysis of variance and a significant difference of means was evaluated as $p<0.05$ as detailed elsewhere $(26,27)$.

RESULTS

\section{Liver lipids}

Average total food intake was slightly but significantly lower in rats fed safflower phospholipid than in those fed soybean oil and hydrogenated soybean phospholipid (Table 3). Body weight at sacrifice was the lowest in fasted rats but no significant differences were seen in this parameter among rats fed the fat-free diet and diets containing various lipid sources. Compared to the fat-free diet or the diet containing soybean oil, those containing phospholipids significantly reduced the liver weight of the animals. Hepatic concentrations of triacylglycerol were comparable between the rats fed fat-free and soybean oil diets. Soybean and safflower phospholipids 


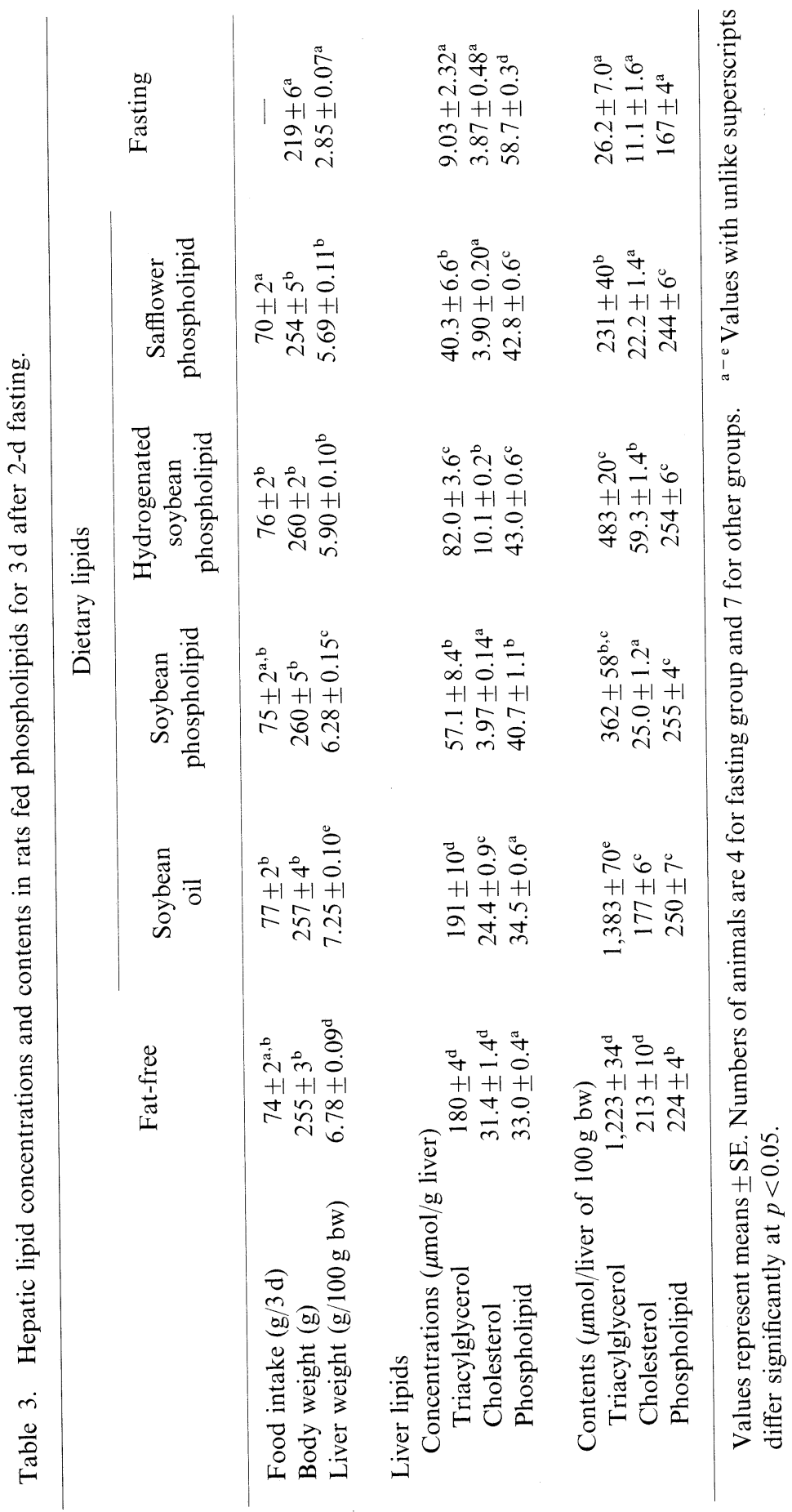

Vol 45, No 3, 1999 
greatly reduced this parameter. Although the extent of reduction was somewhat attenuated, hydrogenated soybean phospholipid also reduced the hepatic concentration of triacylglycerol. As dietary phospholipid reduced the liver weight in the animals, the extent of reduction was exaggerated when hepatic triacylglycerol levels were expressed in contents ( $\mu \mathrm{mol} /$ liver $100 \mathrm{~g}$ bw). Triacylglycerol concentration and content were extremely low in fasted rats. Hepatic cholesterol concentration and content were also lower in rats fed phospholipids than in those fed the fat-free and soybean oil diets. Again, the extent of the reduction was somewhat attenuated in the rats fed hydrogenated soybean phospholipid. Among the fasted-refed groups, compared to the fat-free and soybean oil diets, diets containing phospholipids significantly increased hepatic phopsholipid concentration. When phospholipid levels were expressed as content, however, they were comparable among the fasted-refed groups except for a slight reduction in the rats fed a fat-free diet. Hepatic phospholipid concentration was highest in the fasted rats among groups, while the lipid level was the least when expressed by content.

\section{Enzyme activity in fatty acid synthesis}

Because of the considerable differences in liver weight among the groups, hepatic enzyme activity in fatty acid synthesis was expressed in both specific (nmol/min per mg protein) and total ( $\mu \mathrm{mol} /$ liver of $100 \mathrm{~g} \mathrm{bw}$ ) activity (Table 4$)$. As expected, enzyme activity in fatty acid synthesis was extremely low in fasted rats. A subsequent 3-d refeeding greatly increased activity, with the increase dependent on the type of diet. A diet containing soybean oil at a $4 \%$ fatty acid level, compared to the fat-free diet, caused a $15 \%$ reduction in specific activity of fatty acid synthetase and malic enzyme, but did not cause a significant change in the specific activity of glucose 6-phosphate dehydrogenase and pyruvate kinase. Soybean oil did not significantly affect all the enzyme activity when it was expressed in total activity. Compared to the fat-free and soybean oil diets, diets containing phospholipids significantly decreased the specific and total activities of fatty acid synthetase, malic enzyme, and glucose 6-phosphate dehydrogenase. Reductions were comparable between soybean and safflower phospholipids and somewhat attenuated with hydrogenated soybean phospholipid. Although differences were not necessarily statistically significant, the specific activity of pyruvate kinase was lower in the rats fed phospholipids than in those fed the fatfree and soybean oil diets. Because of the considerable decrease in liver weight, reduction in enzyme activity by dietary phospholipids was exaggerated when expressed in total activity. Reduction was somewhat greater with safflower phospholipid than with soybean phospholipid and its hydrogenation product.

\section{Gene expression}

The hepatic abundance of mRNA for enzymes in fatty acid synthesis was determined by dot-blot hybridization using specific cDNA probes and expressed as relative values, assigning the value in rats fed the fat-free diet as 100 (Table 5). 


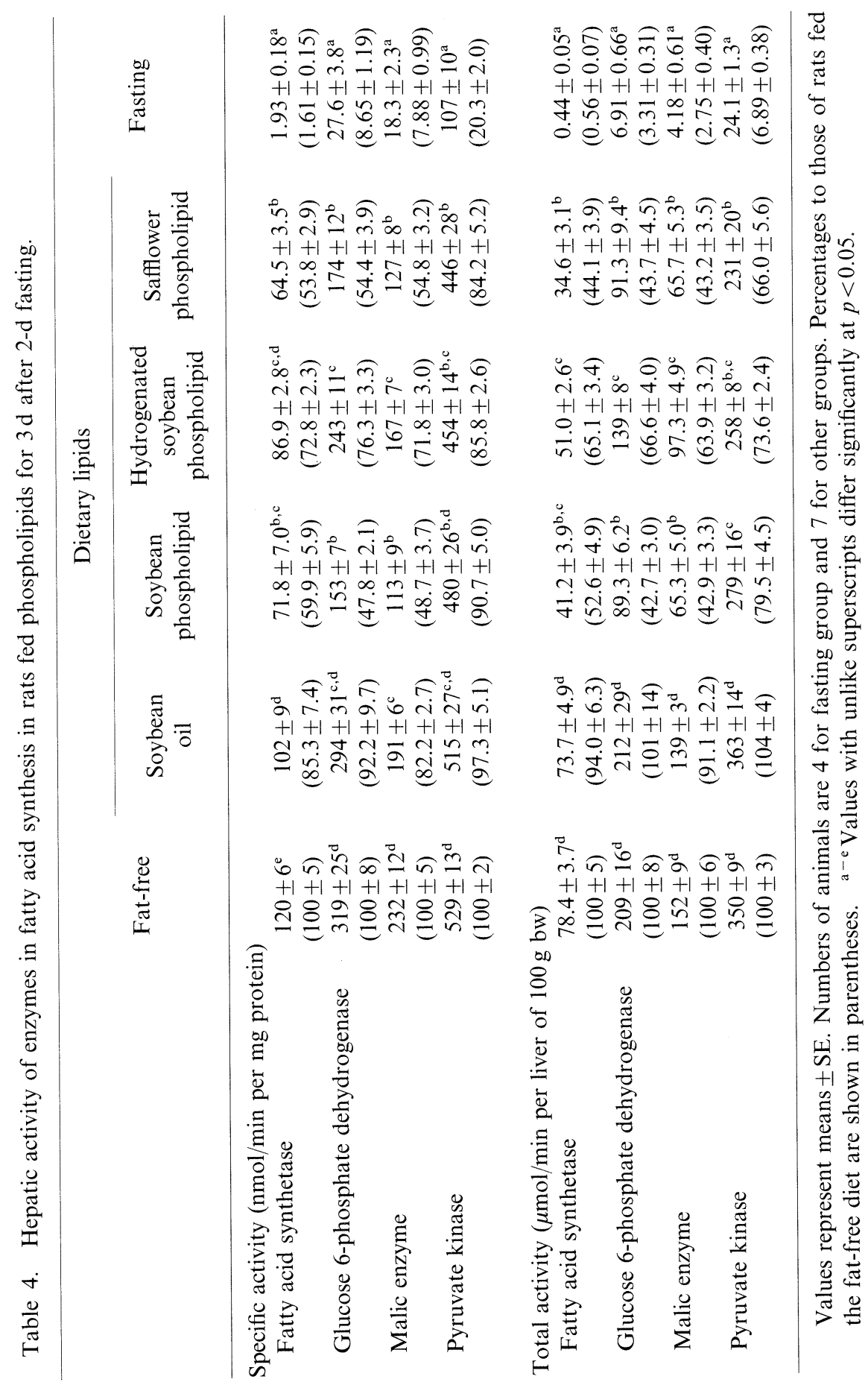

Vol 45, No 3, 1999 


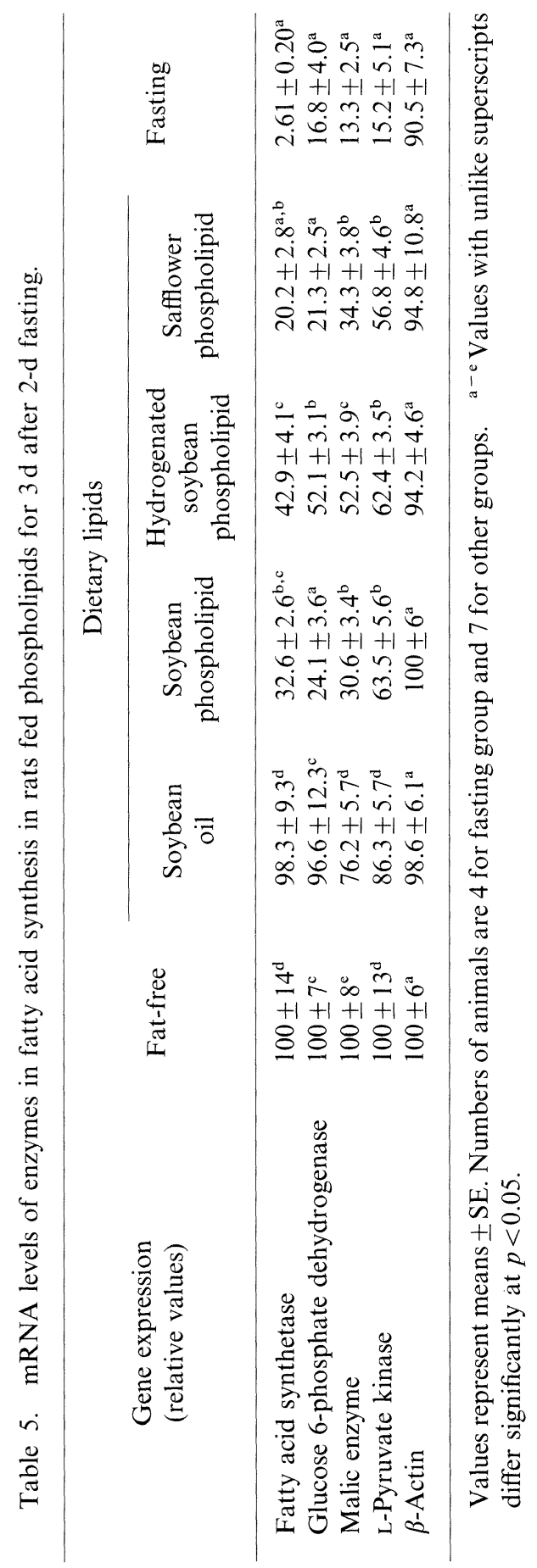


Mammals have four types of pyruvate kinase named $\mathrm{L}, \mathrm{M}_{1}, \mathrm{M}_{2}$ and $\mathrm{R}$. The $\mathrm{L}$ type is the major isozyme in the liver. $\mathrm{M}_{1}$ predominates in muscle, heart, and brain. $\mathrm{M}_{2}$ is found only in fetal tissues, and $\mathrm{R}$ is specifically located in red cells (28). We therefore used cDNA for the $\mathrm{L}$ isozyme as a probe to detect hepatic pyruvate kinase mRNA. Using this probe, mRNA signal was detected in RNA preparation in the liver but not in the muscle by Northern blot analysis (data not shown), indicating that this probe at least discriminates between $\mathrm{L}$ and $\mathrm{M}_{1}$ mRNAs. As expected, mRNA levels for enzymes in fatty acid synthesis were very low in fasted rats. Compared to the fat-free diet, the soybean oil diet did not significantly decrease enzyme mRNA levels except for malic enzyme. Phospholipid preparations effectively reduced the gene expression of enzymes in fatty acid synthesis. The reduction in gene expression of fatty acid synthetase, glucose 6-phosphate dehydrogenase, and malic enzyme was somewhat attenuated with hydrogenated soybean phospholipid as compared to soybean and safflower phospholipids, but these phospholipids were equally effective in reducing the gene expression of L-pyruvate kinase. The mRNA abundance of a house-keeping gene ( $\beta$-actin) was the same among all groups. Typical results for Northern blot analysis of hepatic RNA from fasted-refed rats are shown in Fig. 1. These results confirmed those obtained with dot-blot hybridization.

\section{DISCUSSION}

We previously demonstrated that, compared to the diets containing soybean oil or the fat-blend simulating fatty acid composition of soybean phospholipid, dietary soybean phospholipid markedly reduced triacylglycerol synthesis parameters in the liver (1-3). An analysis of the concentrations of intermediates in triacylglycerol synthesis and activity of enzyme in triacylglycerol and fatty acid synthetic pathways indicated that the reduction in fatty acid availability due to decreased fatty acid synthesis is the primary factor for soybean phospholipid-dependent reduction in triacylglycerol synthesis in the liver. Results obtained using hepatocytes isolated from rats fed soybean phospholipid also support this consideration (4). Our previous observations $(1,3)$ also indicated that egg yolk phospholipid is as effective as soybean phospholipid in reducing fatty acid and triacylglycerol synthesis in the rat liver. Thus, it is suggested that phospholipids of various origins can potentially reduce lipogenic activity in the liver. Consistent with this assumption, the present study unequivocally demonstrated that phospholipid originating from safflower seeds also effectively reduced the hepatic activity of enzyme in fatty acid synthesis.

Various nutritional and physiological conditions alter the hepatic abundance of mRNAs for enzymes in fatty acid synthesis $(10-12,15,29)$. It has also been shown that hepatic mRNA levels correlated well with the enzyme activity and protein content of translational products $(10,11,15,29)$. We confirmed that phospholipids decreased the hepatic abundance of mRNAs for fatty acid synthetase, malic enzyme, glucose 6-phosphate dehydrogenase, and L-pyruvate kinase 


\section{$\begin{array}{llllllllll}1 & 2 & 3 & 4 & 5 & 6 & 7 & 8 & 9 & 10\end{array}$}
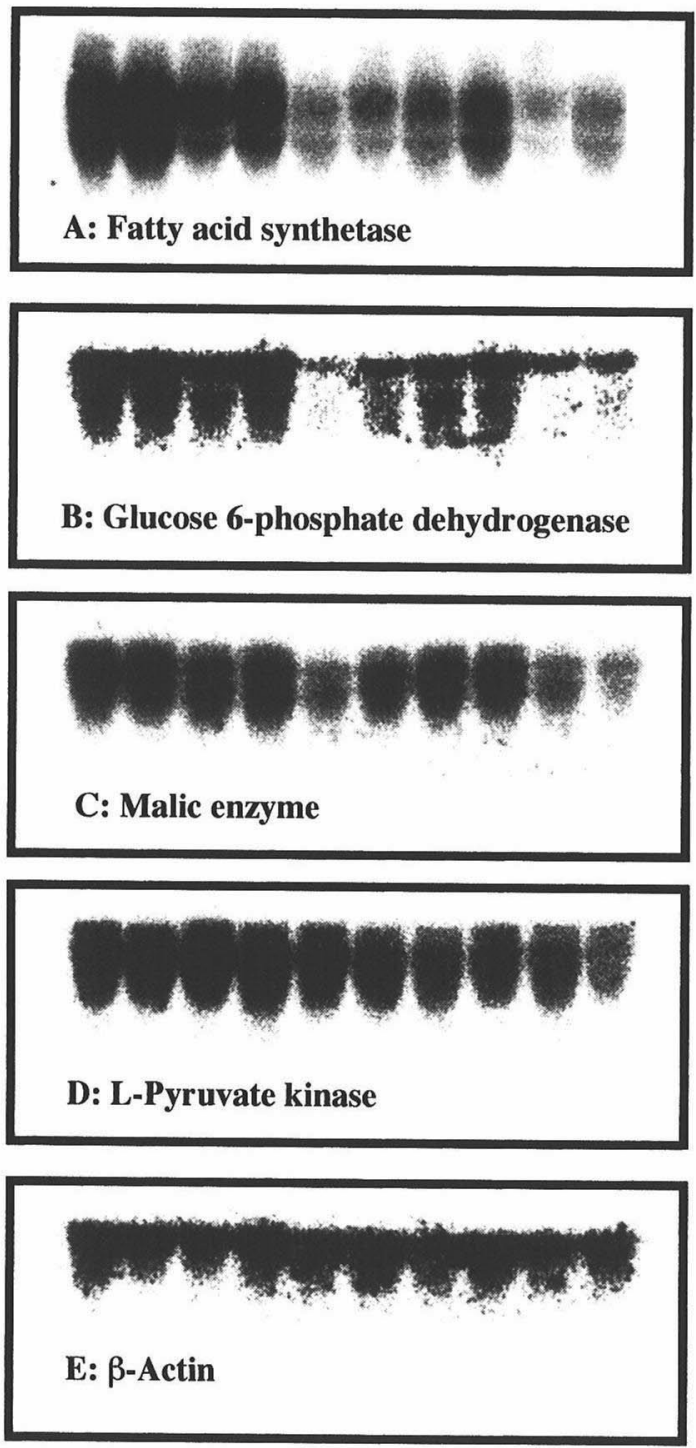

Fig. 1. Northern blot analysis of hepatic RNA from fasted-refed rats. RNA samples $(40 \mu \mathrm{g})$ were denatured and electrophoresed on $1.1 \%$ agarose gel containing $0.66 \mathrm{M}$ formaldehyde, transferred to a nylon membrane and fixed with UV irradiation. RNAs in nylon membranes were hybridized with radiolabeled cDNA probes specific for mRNAs of fatty acid synthetase (A), glucose 6-phosphate dehydrogenase (B), malic enzyme (C), L-pyruvate kinase (D) and $\beta$-actin (E). Lanes 1 and 2, RNAs from rats fed a fat-free diet; 3 and 4, soybean oil diet; 5 and 6 , soybean phospholipid diet; 7 and 8 , hydrogenated soybean phospholipid diet; 9 and 10 , safflower phospholipid diet. 
accompanying reductions in the activities of these enzymes. Alterations of mRNA levels by phospholipids generally paralleled enzyme activity. It is therefore conceivable that dietary phospholipids decreased mRNA levels and thus altered the translational rate and activities of enzymes in fatty acid synthesis in the liver. Modifications in the abundance of mRNAs encoding enzymes in fatty acid synthesis have been attributed to alterations in transcriptional rate, mRNA stability, and (or) processing of precursor mRNA to mature mRNA (10-12). At present, it is not clear which of these processes dietary phospholipids affect and thus reduce mRNA levels. Further study is needed to clarify this point to understand the molecular mechanism underlying dietary phospholipid-dependent reduction in hepatic fatty acid synthesis.

Polyunsaturated but not saturated and monounsaturated fatty acids are dietary factors to decrease mRNA abundance and the activity of hepatic enzymes in fatty acid synthesis (10-15). Both soybean and safflower phospholipids contained considerable amounts of polyunsaturated fatty acids, so it is possible that the fatty acid moiety of the phospholipid is responsible for reducing the mRNA level and activity of enzymes in fatty acid synthesis. We previously showed that the activity of enzymes in fatty acid synthesis and triacylglycerol level in the liver of rats fed a diet containing $20 \%$ soybean oil for $3 \mathrm{~d}$ after 2 -d fasting were about one-half those observed in rats refed a fat-free diet (2). However, diets containing 2 and $5 \%$ fatty acids as soybean oil relative to a fat-free diet caused merely $20-25 \%$ decreases in the hepatic activity of enzymes in fatty acid synthesis, and were totally ineffective in decreasing the hepatic triacylglycerol level. In this situation, soybean phospholipid added to experimental diets at 2 and 5\% fatty acid levels caused $45-50$ and $65-75 \%$ decreases, respectively, in the activity of enzymes in fatty acid synthesis, accompanying a profound reduction in the hepatic triacylglycerol levels. In an another one of our studies (3), a fat-blend simulating fatty acid composition of soybean phospholipid at a 3\% fatty acid level caused a $20-25 \%$ decrease in the activity of enzymes in fatty acid synthesis, but diets containing phospholipids of soybean and egg yolk origins at the same fatty acid level caused $60-80 \%$ decreases in this parameter in fasted-refed rats. In the present study, a diet containing soybean oil at a $4 \%$ fatty acid level relative to a fat-free diet only marginally decreased the activity of enzymes in fatty acid synthesis. However, compared both to the fat-free and soybean oil diets, those containing soybean and safflower phospholipids at a $4 \%$ fatty acid level greatly reduced the activity and level of mRNA for enzymes in fatty acid synthesis and the triacylglycerol level in the liver of fasted-refed rats. The hydrogenation of soybean phospholipid somewhat attenuated its physiological activity in reducing indices in lipid biosynthesis, but the hydrogenation product lowered the activity and mRNA level of enzymes in fatty acid synthesis more than soybean oil. Therefore, it is difficult to ascribe the potent physiological activity of phospholipids in reducing fatty acid synthesis entirely to polyunsaturated fatty acid moiety. In this context, Imaizumi et al $(30,31)$ suggested that base moiety rather than fatty acid moiety is responsible for the 
cholesterol lowering effect of dietary phospholipids. It has been demonstrated that hydrogenated long-chain triacylglycerol is poorly absorbed in the intestine (13). So, it is also plausible that hydrogenation of phospholipids render the lipid molecule to be less absorbable. The attenuation by hydrogenation of physiological activity of soybean phospholipid in reducing fatty acid synthesis may be ascribable to its low absorbability rather than to the lack of polyunsaturated fatty acid in the molecule.

Various experimental conditions including composition of the experimental diet $(32,33)$, age of animals (29), length of feeding period (14), feeding schedule (ad libitum feeding, meal feeding, and fasting-refeeding) $(13-15,29,32,33)$ appear to influence the inhibition of lipogenesis by polyunsaturated fat. We observed in previous $(2,3)$ and current studies that feeding of polyunsaturated fat at low dietary levels $(2$ to $5 \%$ ) for $3 \mathrm{~d}$ following 2 -d fasting only marginally affect the indices of hepatic fatty acid synthesis in the rat as described above. Iritani et al $(15,29)$ obtained a more profound reduction of the hepatic activity of enzymes in fatty acid synthesis by polyunsaturated fats in fasted-refed rats. They showed that 4-d feeding of a diet containing 5\% corn oil following 2-d fasting caused more than $50 \%$ reduction in the hepatic activity of enzymes in fatty acid synthesis in the rat (29). In an another one of their studies (15), when rats consumed experimental diets containing $10 \%$ hydrogenated beef tallow for $3 \mathrm{~d}$ after 2 -d fasting, substitution of the hydrogenated fat with perilla oil at 2 and 5\% levels caused $25-50 \%$ and 40 $70 \%$ reductions, respectively, in the activity of enzymes in fatty acid synthesis, accompanying parallel decreases in their mRNA levels in the liver. There is a possibility that differences in the basal composition of experimental diets caused the different responses of hepatic fatty acid synthesis to polyunsaturated fat in fasted-refed rats. Rats consumed the diet containing both corn starch and sucrose in our present and previous studies, but they employed sucrose as a sole dietary carbohydrate source in their experimental diet. In this context, Kim and Elson (32) showed that, in rats, 2 -d feeding of a diet containing safflower oil as high as $16 \%$ level after 2-d fasting caused no significant reduction in hepatic activity of fatty acid synthetase when corn starch was employed as the carbohydrate source, but it did cause a $40 \%$ reduction in this parameter when the carbohydrate source was sucrose.

In conclusion, phospholipids of soybean and safflower seed origins added to diets at a $4 \%$ fatty acid level profoundly reduced the abundance of mRNAs encoding enzymes in fatty acid synthesis, accompanying reductions in enzyme activity and triacylglycerol levels in the livers of fasted-refed rats. However, soybean oil at this dietary level only marginally lowered the enzyme activity and mRNA levels and failed to reduce the triacylglycerol level in the liver. Hydrogenated soybean phospholipid, compared to soybean oil, was still effective in reducing these parameters. Polyunsaturated fatty acids contained in phospholipid preparations at this dietary level therefore cannot account for the potent physiological activity in reducing hepatic fatty acid synthesis in fasted-refed rats. 


\section{REFERENCES}

1) Ide T, Murata M, Moriuchi H. 1992. Microsomal triacylglycerol synthesis and diacylglycerol concentration in the liver of rats fed soybean and egg yolk phospholipids. Biosci Biotech Biochem 56: 732-735.

2) Ide T, Hirabayashi S, Kano S, Sugano M. 1992. Soybean phospholipid dependent reductions in triacylglycerol concentration and synthesis in the liver of fasted-refed rats. Biochim Biophys Acta 1124: 163-170.

3) Ide T, Murata M. 1994. Depression by dietary phospholipids of soybean and egg yolk origins of hepatic triacylglycerol and fatty acid synthesis in fasted-refed rats. Ann Nutr Metab 38: 340-348.

4) Ide T, Murata M, Sunada Y. 1994. Triacylglycerol and fatty acid synthesis in hepatocytes in suspension isolated from rats fed soybean phospholipid. Biosci Biotech Biochem 58: 699-702.

5) Kabir Y, Ide T. 1995. Effect of dietary soybean phospholipid and fats differing in the degree of unsaturation on fatty acid synthesis and oxidation in rat liver. $J$ Nutr Sci Vitaminol 41: 635-645.

6) Imaizumi K, Sakono M, Nagata J, Sugano M, Kitsugi H, Amano, K. 1988. Lipid and eicosanoid levels in rats fed $\gamma$-linolenic acid as triglyceride or phospholipid of the mold origin. Nutr Rept Intern 38: 767-772.

7) Iwata T, Hoshi S, Tsutsumi K, Furukawa Y, Kimura S. 1991. Effect of dietary safflower phospholipid on plasma and liver lipids in rats fed a hypercholesterolemic diet. $J$ Nutr Sci Vitaminol 37: 591-600.

8) Iwata T, Hoshi S, Takehisa F, Tsutsumi K, Furukawa Y, Kimura S. 1992. The effect of dietary safflower phospholipid and soybean phospholipid on plasma and liver lipids in rats fed a hypercholesterolemic diet. J Nutr Sci Vitaminol 38: 471-479.

9) Iwata T, Ohya K, Takehisa F, Tsutsumi K, Furukawa Y, Kimura S. 1992. The effect of dietary safflower phospholipid on steroids in gastrointestinal tract of rats fed a hypercholesterolemic diet. J Nutr Sci Vitaminol 38: 615-622.

10) Iritani N. 1992. Nutritional and hormonal regulation of lipogenic-enzyme gene expression in rat liver. Eur J Biochem 205: 433-442.

11) Hillgartener F, Salati LM, Goodridge AG. 1995. Physiological and molecular mechanism involved in nutritional regulation of fatty acid synthesis. Physiol Rev 75: 47-76.

12) Clarke SD, Jump DB. 1996. Polyunsaturated fatty acid regulation of hepatic gene expression. Lipids 31: S-7-S-11.

13) Triscari J, Hamilton JC, Sullivan AC. 1978. Comparative effect of saturated and unsaturated lipids on hepatic lipogenesis and cholesterogenesis in vivo in the meal-fed rat. $J$ Nutr 108: 815-823.

14) Clarke SD, Romsos DR, Leveille GA. 1977. Time sequence of changes in hepatic fatty acid synthesis in rats meal-fed polyunsaturated fatty acids. J Nutr 107: 1468-1476.

15) Iritani N, Komiya M, Fukuda H, Sugimoto T. 1998. Lipogenic enzyme gene expression is quickly suppressed in rats by a small amount of exogenous polyunsaturated fatty acids. J Nutr 128: 967-972.

16) American Institute of Nutrition. 1977. Report of the American Institute of Nutrition Ad Hoc Committee on standards for nutritional studies. J Nutr 107: 1340-1348.

17) Kelley DS, Nelson GJ, Hunt JE. 1986. Effect of prior nutritional status on the activity of lipogenic enzymes in primary monolayer cultures of rat hepatocytes. Biochem J 235: 
$87-90$.

18) Kelley DS, Kleitzien RF. 1984. Ethanol modulation of hormone and nutritional regulation of glucose 6-phosphate dehydrogenase activity in primary cultures of rat hepatocytes. Biochem J 217: 543-549.

19) Hsu RY, Lardy HA. 1969. Malic enzyme. Methods Enzymol 13: 230-235.

20) Tanaka T, Harano Y, Sue F, Morimura H. 1967. Crystallization, characterization and metabolic regulation of two types of pyruvate kinase isolated from rat tissues. $J$ Biochem 62: 71-91.

21) Folch J, Lees M, Sloane-Stanley GH. 1957. A simple method for the isolation and purification of total lipids from animal tissues. J Biol Chem 226: 497-509.

22) Ide T, Okamatsu H, Sugano M. 1982. Regulation by dietary fats of 3-hydroxy-3methylglutaryl-coenzyme A reductase in rat liver. $J$ Nutr 108: 601-612.

23) Ide T, Oku H, Sugano M. 1982. Reciprocal response to clofibrate in ketogenesis and triglyceride and cholesterol secretion in isolated rat liver. Metabolism 31: 1065-1072.

24) Magnuson MA, Morioka H, Tecce MF, Nikodem VM. 1986. Coding nucleotide sequence of rat liver malic enzyme mRNA. J Biol Chem 261: 1183-1186.

25) Chomczynski P, Sacchi N. 1987. Single-step method of RNA isolation by acid guanidium thiocyanate-phenol-chloroform extraction. Anal Biochem 162: 156-159.

26) Snedecor GW, Cochran WG. 1989. Statistical Methods, 8th ed, Iowa University Press, Ames.

27) Ide T, Kano S, Yanagita T, Sugano M. 1994. Dietary modifications of the biliary bile acid glycine:taurine ratio and activity of hepatic bile acid-CoA:amino acid $N$-acyltransferase (EC 2.3.1) in the rat. Br J Nutr 72: 93-100.

28) Inoue H, Noguchi T, Tanaka T. 1986. Complete amino acid sequence of rat L-type pyruvate kinase deduced from the cDNA sequences. Eur J Biochem 154: 465-469.

29) Fukuda H, Katsurada A, Iritani N. 1987. Effect of aging on conditions of dietary fat and triiodothyronine treatment to lipogenic enzyme induction. Biochim Biophys Acta 921: 43-49.

30) Imaizumi K, Mawatari K, Murata M, Ikeda I, Sugano M. 1983. The contrasting effect of dietary phosphatidylethanolamine and phosphatidylcholine on serum lipoproteins and liver lipids in rats. $J$ Nutr 113: 2403-2411.

31) Murata M, Imaizumi K, Sugano M. 1982. Effect of dietary phospholipids and their constituent bases on serum lipids and apolipoproteins in rats. J Nutr 112: 1805-1808.

32) Kim M, Elson CE. 1981. Comparative studies of adaptive responses of fatty acid synthetase activities in rat liver and adipose tissue. J Nutr 111: 1985-1995.

33) Herzberg GR, Rogerson M. 1981. Dietary corn oil does not suppress the fructose induced increase in hepatic fatty acid synthesis. Nutr Res 1: 73-77. 